\title{
LOS DERECHOS DE IGUALDAD EN EL CONSTITUCIONALISMO CONTEMPORÁNEO
}

\author{
MIGUEL CARBONELL ${ }^{*}$
}

RESUMO: O artigo aborda diferentes perspectivas da noção de igualdade, a lógicolingüística, a filosófico-política e a jurídica, estabelecendo assim as bases para uma análise mais aprofundada de determinados tópicos atuais da aplicação do principio da igualdade, como as ações afirmativas e as cotas no sistema eleitoral.

PALAVRAS-CHAVE: Igualdade. Direito Constitucional. Ações Afirmativas. Cotas. México.

ABSTRACT: The article takes on different perspectives of the equality notion, the logical-linguistic one, the philosophical-political one and the legal one, thus establishing the field for a more profound analysis of certain current topics in the application of the equality principle, such as affirmative action and electoral system quotas.

KEYWORDS: Equality. Constitutional Law. Affirmative Action. Quotas. Mexico.

SUMÁRIO: 1. Introdução ao conceito de igualdade; 1.1. Igualdade e justiça; 1.2. Perspectivas sobre a igualdade; 1.2.1. A perspectiva lógico-lingüística; 1.2.2. A perspectiva filosóficopolítica; 1.2.3. A perspectiva jurídica; 1.3. Quais diferenças são relevantes? 1.4. Igualdade na aplicação da lei e igualdade perante a lei; 2 . A igualdade em sentido substancial; 2.1. As ações afirmativas; 2.2. As cotas eleitorais de gênero; 2.3. As razões a favor e contra as cotas eleitorais de gênero; 2.4. As cotas e o direito internacional dos direitos humanos; Referências.

SUMMARY: 1. Introduction to the concept of equality; 1.1. Equality and justice; 1.2. Perspectives on equality; 1.2.1. The logical-linguistic perspective; 1.2.2. The philosophical-political perspective; 1.2.3. The legal perspective; 1.3. Which perspectives are relevant? 1.4. Equality in applying the Law and equality before the Law; 2. Equality in substantial sense; 2.1. Affirmative Action policies; 2.2. Gender electoral quotas; 2.3. The reasons favoring and disfavoring gender electoral quotas; 2.4. Quotas and the international law of human rights; References.

SUMARIO: 1. Introducción al concepto de igualdad; 1.1. Igualdad y justicia; 1.2. Perspectivas sobre la igualdad; 1.2.1. La perspectiva lógico-lingüística; 1.2.2. La perspectiva filosófico-política; 1.2.3. La perspectiva jurídica; 1.3. ¿Qué diferencias son relevantes?; 1.4. Igualdad en la aplicación de la ley e igualdad ante la ley; 2 . La igualdad en sentido sustancial; 2.1. Las acciones positivas; 2.2. Las cuotas electorales de género; 2.3. Las razones a favor y en contra de las cuotas electorales de género; 2.4. Las cuotas y el derecho internacional de los derechos humanos; Referencias.

Artigo recebido em 5.06.2010 - Cota de Convite.

Aprovado para publicação pelo Conselho Editorial em 07.07.2010.

* Professor do Instituto de Investigações Jurídicas da Universidade Nacional Autônoma do México, Cidade do México.

DIREITOS FundaMentaIS E JUSTIÇA N' 11-ABR./Jun. 2010 


\section{INTRODUCCIÓN AL CONCEPTO DE IGUALDAD}

El de igualdad es un concepto complejo, que atañe por igual a diversas áreas de las ciencias sociales. Ha sido estudiado lo mismo por la economía, la política, la sociología, la antropología y el derecho ${ }^{1}$.

Se trata, sin embargo, de una noción particularmente elusiva, cargada con frecuencia de connotaciones partidistas y afectada casi siempre por posicionamientos ideológicos. Como señala Francisco J. Laporta, "La idea de igualdad pasa por ser uno de los parámetros fundamentales del pensamiento social, jurídico y político de nuestro tiempo. Pero, por desgracia, su importancia como idea regulativa básica no va regularmente acompañada ni por la claridad de formulación ni por la precisión de su sentido y límites. Suele ser, más bien, un concepto muy discutido en torno al cual surgen frecuentes desacuerdos prácticos y pugnas teóricas importantes”2.

Para el pensamiento constitucional el principio de igualdad ha tenido en el pasado, tiene en la actualidad y está llamado a tener en el futuro una importancia capital. Desde el nacimiento mismo del Estado constitucional la igualdad no ha dejado de figurar como uno de los principios vertebradores de dicho modelo de Estado.

El primer artículo de que lo que, junto con la Constitución norteamericana de 1787, podría considerarse el acta de nacimiento del constitucionalismo moderno, la Declaración de los Derechos del Hombre y el Ciudadano de 1789, tiene por objeto justamente el principio de igualdad: "Los hombres nacen y permanecen libres e iguales en derechos. Las distinciones sociales sólo pueden fundarse en la utilidad común”3.

De la misma forma, también el pensamiento ilustrado había reparado en la importancia del principio de igualdad. Podrían ser muchas las citas que se hicieran al respecto, pero quizá hay dos que recogen fielmente la postura ilustrada que sirvió para alimentar la filosofía de las primeras declaraciones de derechos. La primera es de Hobbes, quien en su obra De Cive escribió: "Si la naturaleza he hecho iguales a los hombres, esta igualdad debe ser reconocida; si les ha hecho desiguales, puesto que se pelearán por el poder, es necesario para lograr la paz que se consideren como iguales”. La segunda cita es de Rousseau, quien señaló en El Contrato Social que "Es que en lugar de destruir la igualdad natural, el pacto fundamental sustituye, por el contrario, por una igualdad moral y legítima lo que la naturaleza pudo poner de desigualdad física entre los hombres y que, pudiendo ser desiguales en fuerza o en genio, se vuelven todos iguales por convención y derecho... Precisamente porque la fuerza de las cosas tiende siempre a destruir la igualdad es por lo que la fuerza de la legislación debe tender siempre a mantenerla”.

\footnotetext{
${ }^{1}$ Tiene razón Gosta Esping-Andersen cuando afirma que "En el sentido más amplio posible, la igualdad constituye el principal leivmotiv de la ciencia social. En economía se hace hincapié en la distribución (y la utilización) de los recursos escasos; en ciencias políticas se insiste más en el poder; y en sociología, en la estratificación social”, Fundamentos sociales de las economías postindustriales, Barcelona, Ariel, 2000, p. 16.

${ }^{2}$ Laporta, Francisco J., "El principio de igualdad: introducción a su análisis”, Sistema, número 67, Madrid, 1985, p. 3.

${ }^{3}$ Un análisis de este precepto y de la Declaración en su conjunto puede verse en Carbonell, Miguel, Una historia de los derechos fundamentales, México, Porrúa, CNDH, 2005, capítulo III.
} 


\subsection{Igualdad y justicia.}

Aparte de lo anterior, la igualdad dentro del pensamiento filosófico de la modernidad ha estado vinculada al concepto más amplio de justicia. Esto es lo que explica que la más importante formulación teórica sobre la justicia que se realizó en el siglo XX, la famosa Teoría de la justicia de John Rawls, afirme como los dos grandes principios de justicia cuestiones que están inmediatamente relacionadas con la igualdad. Para Rawls los dos principios a partir de los cuales habría que comenzar a edificar una sociedad justa (partiendo de lo que el propio Rawls llama "la posición originaria”) son los siguientes ${ }^{4}$ :

Primer principio: Cada persona ha de tener un derecho igual al esquema más extenso de libertades básicas que sea compatible con un esquema semejante de libertades para los demás.

Segundo principio: Las desigualdades sociales y económicas habrán de ser conformadas de modo tal que a la vez que: a) se espere razonablemente que sean ventajosas para todos, b) se vinculen con empleos y cargos asequibles para todos.

Como se puede ver, el nexo que establece Rawls entre justicia e igualdad es inequívoco ${ }^{5}$. A partir del primer principio se podría construir el mandato constitucional de la igualdad en los derechos fundamentales, mandato que se suele recoger en todos los textos constitucionales de nuestros días (así sucede en el párrafo primero del artículo 1 de la Constitución mexicana vigente). En la última parte del primer principio también está implícita la idea de que las libertades básicas (concepto que podríamos ampliar para incluir a todos los derechos fundamentales) no se pueden restringir con cualquier argumento, sino solamente en la medida en que así lo exija la necesidad de que todas las personas tengan el mismo esquema de libertades (es decir, se trata del conocido principio según el cual mi derecho puede llegar hasta donde comienza el de otra persona; cuestión que en la práctica no es fácil de dilucidar, pero que como principio normativo es irrebatible).

El segundo principio parte de la idea de que la regla debe ser la igualdad; las desigualdades deben ser la excepción y solamente se pueden tolerar bajo las dos circunstancias que enumera en el mismo principio. De esas dos circunstancias o condiciones también se pueden extraer interesantes consecuencias para la fundamentación de los derechos de igualdad previstos por el orden constitucional; según la primera de ellas, podemos justificar el criterio de "protección de los más débiles", que tiene mucha relevancia en el ámbito de los derechos sociales, como lo veremos oportunamente; solamente a partir de la protección preferente de los más débiles podemos justificar que una desigualdad sea ventajosa para todos.

\footnotetext{
${ }^{4}$ Rawls, John, Teoría de la justicia, traducción de María Dolores González, México, FCE, 2002 (reimpresión), pp. 67-68.

${ }^{5}$ Sobre la teoría de Rawls se han escrito infinidad de libros y artículos; su libro ha sido uno de los más citados dentro de las ciencias sociales desde su aparición en 1971; para una introducción a su teoría, en relación con el principio de igualdad, Kymlicka, Will, Filosofía política contemporánea, traducción de Roberto Gargarella, Barcelona, Ariel, 1995, pp. 63 y ss.
} 
De acuerdo con la segunda circunstancia podemos construir y fundamentar el principio de igualdad de oportunidades que subyace al mandato de igualdad formal ante la ley; es decir, para que una desigualdad esté justificada, debe darse una igualdad de oportunidades a todos los miembros de una sociedad, de manera que los "empleos y cargos" (podríamos ampliar esta idea para hacerla extensiva a todos los bienes socialmente relevantes, o por lo menos a todos los bienes básicos) sean realmente asequibles a todos; a partir de este principio podrían justificarse, por ejemplo, las cuotas electorales de género, cuyo estudio pormenorizado se realiza en la parte final de este mismo capítulo. Es importante destacar que para Rawls los “empleos y cargos” deben ser realmente asequibles a partir de la igualdad de oportunidades; es decir, no solamente se trata de decir que son asequibles en tanto que no hay impedimentos formales para acceder a esos bienes sociales, sino que hay que generar las condiciones necesarias y suficientes para que en efecto exista la posibilidad real de acceder a ellos ${ }^{6}$.

\subsection{Perspectivas sobre la igualdad.}

El tema de la igualdad, en general, puede ser estudiado desde tres niveles distintos de análisis, como recuerda Paolo Comanducci ${ }^{7}$ :

\subsubsection{La perspectiva lógico-lingüística.}

Un primer nivel de análisis de la igualdad es el lógico-lingüístico. En este nivel se busca responder a los problemas que ofrece la pregunta "¿igualdad en qué sentido?”. Se trata de atribuir un significado al vocablo igualdad; el objetivo sería determinar sus usos lingüísticos.

Si acudimos al Diccionario de la Real Academia podemos encontrar que el vocablo "igualdad” proviene del latín “aequalitas” y tiene dos significados generales y un significado específico en matemáticas; en general significa "Conformidad de algo con otra cosa en naturaleza, forma, calidad o cantidad”, así como “Correspondencia o proporción que resulta de muchas partes que uniformemente componen un todo”; en matemáticas significa “equivalencia de dos cantidades o expresiones”.

¿Qué significa decir que dos personas o dos objetos son iguales? Para que dos personas o dos objetos sean iguales deben mantener una relación de igualdad, la cual debe cumplir con tres propiedades: ser reflexiva $(A=A)$, ser simétrica $(A=B, B=A)$ y ser transitiva (si $A=B, B=C$, entonces $A=C)^{8}$.

Para el ámbito de las ciencias sociales es importante recordar que cuando utilizamos el término igualdad normalmente lo hacemos en un sentido normativo y no descriptivo"; es decir, cuando decimos que dos personas son iguales ante la ley lo

\footnotetext{
${ }^{6}$ En este punto la teoría de Rawls quizá pueda empatarse con algunos conceptos desarrollados por las teorías neorrepublicanas, que sostienen la pertinencia de lograr esquemas de "libertad real para todos"; este es, justamente, el empeño de la importante obra de Van Parijs, Philippe, Libertad real para todos, Barcelona, Paidós, 1996.

${ }^{7}$ Comanducci, Paolo, “Uguaglianza: una proposta neo-illuminista”, Analisi e diritto 1992, a cargo de Paolo Comanducci y Riccardo Guastini, Turín, Giappichelli, 1992, pp. 85-87.

${ }^{8}$ Laporta, Francisco J., "Problemas de la igualdad” en Valcárcel, Amelia (compiladora), El concepto de igualdad, Madrid, Editorial Pablo Iglesias, 1994, pp. 67-68.

9 Tomo esta idea de Laporta, Francisco J., "Problemas de la igualdad”, cit., p. 66. En el mismo sentido, Valcárcel, Amelia, "Igualdad, idea regulativa” en idem (compiladora), El concepto de igualdad, cit., pp. 1-15.
} 
que en realidad queremos decir es que la ley debería tratarlas como iguales, porque de otra manera esa ley estaría violando tal o cual artículo de la Constitución o de un tratado internacional.

Nuestra perspectiva es también de carácter normativo en la medida en que, como es obvio, no hay dos personas completamente iguales. A las ciencias sociales lo que le interesa es saber cuáles son las diferencias entre las personas que pueden ser tomadas en cuenta. Así por ejemplo, a la economía le puede interesar la desigualdad de ingresos existente entre dos o más personas, porque de esa manera se puede hacer un cálculo de los impuestos que debe pagar cada una de ellas; la sociología puede tomar en cuenta las distintas formas de agrupamiento familiar que se producen en una sociedad, analizando las causas por las que unas personas tienen ciertos vínculos familiares y otras sostienen una forma diferente de convivencia. Siguiendo a Laporta podemos decir que las ideas de la igualdad o de la desigualdad no están determinadas principalmente por hechos, sino que son producto de la estructura normativa de la sociedad $^{10}$; esa estructura ha sido variable históricamente, razón por la cual, como tendremos ocasión de comprobar más adelante, la igualdad que tenemos en las sociedades contemporáneas -mucha o poca en la práctica, eso es otra cuestión- se ha ido ganando por parcelas, por avances grandes y pequeños, pero no se ha dado de una vez y para siempre.

Al derecho la pregunta que le interesa es la de ¿cómo lograr la igualdad? Para contestar esa pregunta, sin embargo, la ciencia jurídica tiene que tener claras muchas cuestiones que parten del significado lingüístico, pero también de la perspectiva política desde la que puede ser analizada la igualdad. Justamente sobre la igualdad política trata el siguiente apartado.

\subsubsection{La perspectiva filosófico-política.}

El segundo nivel desde el que se puede analizar la igualdad es el filosófico-político. En este nivel se deben afrontar los problemas relacionados con las dos preguntas siguientes: “¿porqué igualdad?” y “¿qué igualdad?”. Se trata, por tanto, de encontrar la justificación de la igualdad como valor a proteger, y de elegir entre los distintos tipos de igualdad. Para poder llevar a cabo dicha elección hay que distinguir primero entre los distintos tipos de igualdad que en general existen (más adelante nos referiremos a los tipos de igualdad que existen desde el punto de vista jurídico). Sobre la justificación de la igualdad como valor ya se ha dicho alguna cosa al tratar los dos principios de justicia de Rawls; toca ahora explorar los tipos de igualdad que puede haber.

Desde una perspectiva filosófico-política, Ronald Dworkin ha distinguido la “igualdad económica” de la "igualdad política"11. La igualdad económica, de acuerdo con el mismo autor, se puede definir de dos modos distintos. El primero es tomando

\footnotetext{
${ }^{10}$ Laporta, Francisco J., “El principio de igualdad: introducción a su análisis”, cit., p. 3. Este autor señala, en consonancia con lo que se acaba de decir, que hay que tener presente que la idea de igualdad es un principio y no una descripción genérica de la sociedad.

${ }^{11}$ Dworkin, Ronald, "Eguaglianza”, Enciclopedie delle Scienze Sociali, volumen III, Roma, Istituto della Enciclopedia Italiana, 1993, pp. 478 y ss.; del mismo autor, Sovereing virtue: the theorie and practice of equality, Cambridge, Harvard University Press, 2000, sobre todo los capítulos 1 y 2, dedicados respectivamente a la igualdad de bienestar y a la igualdad de recursos.
} 
en cuenta los recursos con que cuentan los individuos, de tal forma que la igualdad económica vendría determinada en términos de riqueza o de ingreso. El segundo modo de definir la igualdad económica no tiene que ver con la igualdad de ingresos o de riqueza, sino con el bienestar de las personas, determinada por la cantidad de recursos de que dispone el individuo para la realización de sus fines.

Esta segunda variable, apunta Dworkin, recoge mejor los intereses reales de los individuos, pues se enfoca de manera fundamental al bienestar, haciendo de los recursos un elemento puramente instrumental. La distinción que hace Dworkin es relevante para el entendimiento jurídico de la igualdad, sobre todo en su vertiente de igualdad material, sobre la cual se abunda más adelante.

La igualdad política, por su parte, tiene una estrecha relación con el concepto mismo (o uno de los conceptos posibles) de democracia. En efecto, si por democracia entendemos una forma de gobierno en la que todos los ciudadanos son considerados iguales en la participación política (o en el derecho a ella), entonces habrá que determinar -desde el punto de vista político- el significado de esa igualdad ${ }^{12}$. Böeckenförde señala que "Democracia e igualdad están estrechamente vinculadas. La posesión del poder de ejercer el dominio político y el punto de partida para la legitimación de este poder no puede atribuirse a unos pocos, sino a todos los miembros del pueblo en común y del mismo modo. La igualdad de los derechos políticos es así imprescindible para la democracia. Pues si la democracia se funda en la libertad y en la autodeterminación, tiene que tratarse en ella de una libertad igual y de una autodeterminación para todos; democracia significa también, aquí y siempre, igualdad en la libertad"13.

En términos generales, la igualdad política dentro de una democracia significa que todas las personas que pertenecen a una comunidad -o la amplia mayoría de ellas- pueden participar en la formulación de las normas jurídicas que rigen dentro de esa comunidad y que todas ellas son igualmente elegibles para ocupar los cargos públicos que se determinan por medio del sufragio popular.

Consecuencia de este significado de la igualdad política es el principio de que a cada persona corresponde un voto, es decir, la asignación de "una cuota igual... de participación en el proceso político decisional”, como resultado del reconocimiento de que "los juicios, los pareceres y las orientaciones políticas de todos los individuos considerados... tienen una igual dignidad"14.

Los enfoques que, como el de Bovero al que acabamos de hacer referencia, llaman la atención sobre la igualdad política como forma de tomar decisiones se ubican dentro de lo que Alfonso Ruiz Miguel ha denominado el "modelo procedimental" de la igualdad política. El propio Ruiz Miguel explica que junto al "modelo procedimental” puede ubicarse el "modelo de preferencias", que en vez de poner el acento en

\footnotetext{
12 Bovero, Michelangelo, Una gramática de la democracia. Contra el gobierno de los peores, traducción de Lorenzo Córdova Vianello, Madrid, Trotta, 2002, p. 24.

${ }^{13}$ Böckenförde, Ernst Wolfgang, "La democracia como principio constitucional” en su libro Estudios sobre el Estado de derecho y la democracia, Madrid, Trotta, 2000, pp. 82-83.

${ }^{14}$ Bovero, Una gramática de la democracia, cit., p. 26.
} 
asegurar la igualdad mediante una correcta forma de tomar decisiones (un hombre, un voto, por ejemplo), se propone que la igualdad política se traduzca en la mayor medida posible en la satisfacción de las preferencias de los votantes ${ }^{15}$.

Este segundo modelo es interesante porque añade algún elemento de sofisticación en el entendimiento de la igualdad política; así por ejemplo, si queremos asegurar que las preferencias de los votantes tengan la consideración más igual que sea posible, entonces es probable que tengamos que diseñar un sistema electoral basado en la proporcionalidad, para que los votos de los ciudadanos se traduzcan de la manera más fiel posible en la distribución de los asientos parlamentarios; es obvio que un sistema electoral mayoritario no toma en cuenta el "modelo de las preferencias" tan en serio como lo hace un sistema proporcional, si bien se puede decir que respeta el "modelo procedimental" en tanto asigna a cada ciudadano una cuota igual de voto (uno por persona). En el mismo sentido, si adoptamos el "modelo de las preferencias" probablemente tendremos que hacer un diseño muy cuidadoso de los distritos electorales a fin de que no existan graves desbalances entre unos y otros; así por ejemplo, no sería conforme a ese modelo que en un distrito electoral conformado por 30,000 ciudadanos eligieran el mismo número de representantes que en otro distrito integrado por 300,000 ciudadanos ${ }^{16}$.

La igualdad política seguramente podría verse mejor realizada en un sistema de democracia directa pues en ese sistema se reduce la distancia entre quienes ocupan un puesto público y los simples ciudadanos, consiguiendo de esa forma lo que se ha llamado la "igualdad vertical”"17. Como señala Ruiz Miguel, "la democracia representativa hace que la desigualdad entre gobernantes y gobernados sea radicalmente más marcada, pues los ciudadanos se limitan a elegir a los gobernantes sin capacidad de adoptar directamente las decisiones políticas y, dada la general prohibición del mandato imperativo, no tienen más forma de control decisivo sobre aquéllos que la no elección en la convocatoria siguiente"18.

Ahora bien, toda vez que la posibilidad de establecer sistemas puros de democracia directa en los Estados contemporáneos parece un poco remota por una serie de razones que no es posible estudiar en este momento, el objetivo de la igualdad política consistiría en diseñar mecanismos para que la distancia entre representantes y representados fuera menor de lo que es en la actualidad. Esto se podría lograr, quizá, por medio de la introducción en el texto constitucional de mecanismos de democracia semi-directa.

En cualquier caso, lo interesante para los efectos de este capítulo es considerar que la igualdad política no se agota en fórmulas abstractas ni es una construcción

${ }^{15}$ Ruiz Miguel, Alfonso, “La igualdad política”, Derechos y libertades, número 11, Madrid, enero-diciembre de 2002, pp. 68-71.

${ }^{16}$ La explicación de estos supuestos y su aplicación a casos concretos que han surgido en el derecho español y en el de los Estados Unidos se encuentra en Ruiz Miguel, “La igualdad política”, cit., pp. 82 y ss. Cfr. también, sobre el tema de la igualdad política y la distribución geográfica de las demarcaciones del voto, Sánchez Muñoz, Óscar, "Sistema electoral y principio de igualdad del sufragio" en Pau Vall, Francesc (coordinador), Parlamento y sistema electoral. VI Jornadas de la Asociación Española de Letrados de Parlamentos, Madrid, Aranzadi, 2002, pp. 491 y ss.

${ }^{17}$ Ruiz Miguel, Alfonso, "La igualdad política”, cit., p. 71

${ }^{18}$ Ruiz Miguel, Alfonso, “La igualdad política”, cit., p. 72. 
ideológica, sino que, cuando es tomada en serio, puede provocar interesantes y positivas consecuencias para el sistema constitucional, logrando no solamente el disfrute más pleno de la igualdad en sentido amplio, sino también una mejor protección y realización de los derechos político-electorales.

\subsubsection{La perspectiva jurídica.}

El tercer nivel en el que puede estudiarse la igualdad es el jurídico, que es sobre el que se va a centrar la exposición del resto del capítulo. Se trata de contestar a la pregunta de “¿cómo lograr la igualdad?”. Al estar el principio de igualdad recogido en los textos constitucionales, desde el punto de vista de la dogmática constitucional no tenemos la necesidad de justificarlo como valor, sino de explicar las condiciones para aplicarlo.

El concepto de igualdad, desde el punto de vista normativo, es un concepto indeterminado, que requiere de un esfuerzo creativo importante por parte del intérprete al momento de juzgar si una determinada norma o situación pueden lesionarlo. Tiene razón Francisco Rubio Llorente cuando afirma que

"la igualdad designa un concepto relacional, no una cualidad de una persona, de un objeto (material o ideal), o de una situación, cuya existencia pueda ser afirmada o negada como descripción de esa realidad aisladamente considerada; es siempre una relación que se da al menos entre dos personas, objetos o situaciones. Es siempre el resultado de un juicio que recae sobre una pluralidad de elementos (en el caso límite, al menos una dualidad), los 'términos de la comparación', entre los cuales debe existir al mismo tiempo alguna diversidad, aunque sólo sea espacial y/o temporal, pues de otro modo, como es obvio, no cabría hablar de pluralidad. La diferencia, al menos numérica, entre los elementos comparados es condición de posibilidad del juicio de igualdad"19.

$\mathrm{Al}$ ser un concepto relacional, podemos considerar también que el principio de igualdad tiene un carácter abierto, en un doble sentido ${ }^{20}$. Como ya lo dijimos, el principio de igualdad es abierto históricamente, ya que la valoración de los rasgos que se pueden utilizar para dar un trato diferente a una persona han sido variables a lo largo de los últimos siglos; así por ejemplo, hasta hace poco no era extraño que existiera una diferencia entre los hombres y mujeres al momento de establecer la titularidad del derecho de sufragio; de la misma forma, todavía hasta la mitad del siglo XX, en Estados Unidos existía una separación entre personas de raza blanca y personas de raza negra en el sistema escolar o en el sistema de transporte público; hoy en día, sin embargo, a nadie en su sano juicio se le ocurriría defender que los criterios del sexo o la raza son válidos para tratar de distinta forma a una persona. En un segundo sentido, el principio de igualdad es un principio abierto debido a que no es posible enumerar o hacer un listado de los rasgos que han de ser considerados irrelevantes y que, por tanto, no pueden ser tenidos en cuenta para dar un trato diferente a dos o más personas.

${ }^{19}$ Rubio Llorente, Francisco, La forma del poder. Estudios sobre la Constitución, Madrid, CEC, 1993, p. 640.

${ }^{20}$ Sigo la idea de Laporta, Francisco J., “El principio de igualdad: introducción a su análisis”, cit., pp. 14-15. 


\section{3. ¿Qué diferencias son relevantes?}

Ahora bien, la pregunta que de inmediato debe hacerse a partir del carácter relacional y abierto del principio de igualdad es: ¿cuáles son las diferencias entre las personas que pueden ser relevantes para producir un trato distinto entre ellas? O dicho en otras palabras: ¿cómo sabemos cuándo está permitido tratar de forma distinta a dos personas? ¿Cómo justificamos que una persona tenga un mejor sueldo que otra o que un empresario deba pagar más impuestos que un desempleado? ¿qué es lo que justifica que los menores de edad no puedan ser titulares del derecho de sufragio o que las personas que tienen una discapacidad psíquica no puedan realizar por sí mismas contratos de compra-venta?

Para contestar a esas preguntas tenemos que acudir necesariamente a lo que dispongan los ordenamientos jurídicos concretos, como es obvio; pero, ¿̇y si nosotros tuviéramos la tarea de legislar y tuviéramos que justificar la elección de ciertos criterios y no de otros bajo los cuales no está permitido distinguir entre las personas? ¿Qué haríamos en ese caso? Tendríamos que realizar necesariamente unos "juicios de relevancia”. Es decir, el principio de igualdad nos indica que si entre dos personas existen diferencias irrelevantes, entonces debemos darles un tratamiento igual; pero también nos exige que si esas personas mantienen diferencias relevantes, entonces el tratamiento que el ordenamiento jurídico les otorgue también debe ser distinto. No se trata de otra cosa sino de la conocida fórmula expresada por Aristóteles en La Política cuando afirmaba lo siguiente: "Parece que la justicia consiste en igualdad, y así es, pero no para todos, sino para los iguales; y la desigualdad parece ser justa, y lo es, en efecto, pero no para todos, sino para los desiguales".

Hay muchos criterios para poder determinar cuándo las diferencias pueden ser relevantes a efecto de generar un tratamiento jurídico diferenciado hacia dos personas. Francisco J. Laporta ha elegido cuatro de esos criterios, que me parece que suministran mucha luz sobre este complicado asunto ${ }^{21}$. Para Laporta, un tratamiento diferenciado entre dos personas podría justificarse tomando en cuenta los siguientes criterios:

A) Principio de satisfacción de las necesidades; de acuerdo con este principio, estaría justificado dar un tratamiento diferente a una persona que tiene una necesidad que satisfacer y no darle ese mismo tratamiento a quien no tenga esa necesidad. El problema en este caso sería determinar el concepto mismo de necesidad ${ }^{22}$. Para algunos autores, una necesidad se produce cuando en ausencia de lo necesitado resentimos un daño en alguno de nuestros derechos o en la posibilidad de llevar adelante nuestros planes de vida; otros, sin embargo, consideran que hay que distinguir entre "necesidades básicas", que serían aquellas que son requisitos para realizar cualquier plan de vida (por ejemplo la vida, la salud, la alimentación, la vivienda, puesto que son bienes sin los cuales nadie podría realizar prácticamente ningún plan de vida), y las necesidades aparentes o personales, que serían las que requiere una persona para llevar a cabo un determinado plan de vida (por ejemplo, tener una casa grande, viajar, fumar, etcétera).

${ }^{21}$ Laporta, Francisco J., “El principio de igualdad: introducción a su análisis”, cit., pp. 20 y ss.

22 Una aproximación a este tema puede verse en Añón Roig, María José, Necesidades y derechos. Un ensayo de fundamentación, Madrid, CEC, 1994. 
B) Principio de retribución de merecimientos; de acuerdo con este principio, estaría justificado dar un trato diferente a una persona que tenga un merecimiento, respecto a otra que no lo tenga. Aunque hay muchos ejemplos aplicativos que no generan mucha discusión (por ejemplo que la medalla de oro en una carrera atlética se le debe entregar a quien llegue en primer lugar y no a quien llegue en último lugar; que un alumno que acredite todas las materias debe obtener un título profesional y el que no cumpla con ese requisito no, etcétera), hay algunos supuestos en donde la puesta en práctica del principio de retribución de merecimientos no es tan fácil; esto se debe al hecho de que el concepto de mérito es una construcción social, que depende de la valoración positiva o negativa que podamos tener sobre una conducta determinada; ¿qué sucede, sin embargo, cuando esa conducta no puede ser valorada en términos positivos o negativos?

C) Principio de reconocimiento de aptitudes; de acuerdo con este principio, sería legítimo dar un trato diferenciado a una persona que tuviera ciertos rasgos o características, predominantemente innatas, respecto a otra que no las tuviera; las aptitudes pueden ser características como la inteligencia, la salud, algunos rasgos físicos, la experiencia, etcétera. Las aptitudes se distinguen de los méritos por el hecho de no incorporar de forma preponderamente elementos volitivos; es decir, nuestra voluntad no tiene incidencia sobre la estatura que tenemos o sobre la precisión de nuestra vista. Así por ejemplo, para citar un caso extremo, tendría justificación tratar de forma diferente a una persona que tuviera buena vista respecto de otra que fuera invidente al momento de seleccionar conductores de autobuses. También podría justificarse que las personas que deben desempeñar labores profesionales de alto riesgo tuvieran ciertas características físicas.

Desde luego, este principio tampoco está exento de riesgos y de entrar en conflicto con el principio de no discriminación, que justamente trata -en algunos de sus aspectos- de lograr que las personas no puedan recibir un trato diferente por motivos que no pueden modificar voluntariamente, como por ejemplo el sexo o el color de la piel. En este sentido, la relevancia de las aptitudes tendrá que ser examinada para cada caso en particular; puede ser razonable que para ocupar cierto puesto de trabajo se pidan personas que midan más de 1,80 metros, pero quizá no lo es si además se le pide a esas personas que no sean de raza negra o que no profesen una religión islámica.

D) Principio de consideración de status; según este principio sería legítimo dar un trato diferente -más positivo- a una persona que tenga un cierto status en relación a otra persona que no lo tenga. Por status puede entenderse el hecho de que una persona ocupe una cierta posición social desde una perspectiva sociológica; ejemplo de diferentes status desde este punto de vista serían el ser niño, pobre, médico, mayor de edad, mujer, etcétera. No necesariamente debe tratarse de status que se refieran a situaciones de vulnerabilidad o a grupos vulnerables. En parte, el proceso de especificación de los derechos tiene que ver justamente con la determinación de los status que son relevantes para otorgar derechos diferenciados; si en el primer constitucionalismo los derechos eran reconocidos para todo hombre o para toda persona, el constitucionalismo más reciente ha ido concretando esa asignación para dar cuenta de las posiciones que las personas van adoptando a lo largo de su vida; en consecuencia, los textos constitucionales y los tratados internacionales de derechos 
humanos hablan no del hombre o de la persona en general, sino del niño, del trabajador, del inmigrante, del indígena, del consumidor, del preso, etcétera.

Desde luego, habrá que discutir, nuevamente, cuáles son los status relevantes; ¿porqué el artículo 2 de la Constitución mexicana establece una protección especial para los pueblos y comunidades indígenas y no dice nada sobre los filósofos del derecho de corte analítico?, ¿porqué se protege especialmente a los niños en el artículo 4 constitucional y no a las personas de entre 30 y 40 años que no tienen pareja? De momento basta con apuntar el hecho de que la pertenencia a un cierto grupo determina el que se tenga un determinado status, el cual puede ser tomado en cuenta al momento de juzgar si un determinado tratamiento jurídico diferenciado es o no violatorio del principio de igualdad.

En su trabajo sobre el tema de la igualdad del que hemos tomado los cuatro criterios anteriores, Laporta señala dos consideraciones generales que hay que tener presentes ${ }^{23}$. Por un lado, señala que muchas de las nociones empleadas en los cuatro criterios dependen del contexto social, cultural y lingüístico en el que se quieren aplicar (reiterando de esa forma lo que ya se había dicho sobre el carácter abierto del principio de igualdad). Por otro lado, nos advierte que algunas de esas nociones deben ser tomadas gradualmente, puesto que su presencia o ausencia puede darse en una escala de medida que puede ser muy variable. Así por ejemplo, puede ser relevante el hecho de alcanzar o no un cierto grado de "necesidad", de "merecimientos" o de "aptitudes" (seguramente el criterio de la consideración de status podría ser, en principio, el que menos problemas de gradualidad ofreciera). Esto es lo que produce que, en la práctica, el principio de igualdad esté sujeto en ocasiones al control por medio de la proporcionalidad; es decir, la igualdad será respetada siempre que el trato desigual dado a dos personas sea proporcionado en relación con las normas que consagran el propio principio de igualdad o de otras que les reconozcan o nieguen ciertos derechos. El juicio de proporcionalidad tiene un papel esencial para saber si el principio de igualdad ha sido o no violado ${ }^{24}$.

\subsection{Igualdad en la aplicación de la ley e igualdad ante la ley.}

La teoría jurídica contemporánea y la práctica de algunos tribunales constitucionales han estudiado el principio de igualdad a partir de dos subconceptos del mismo: el principio de igualdad en la aplicación de la ley y el principio de igualdad ante la ley.

El primero consiste en el mandato de trato igual referido a las autoridades encargadas de aplicar la ley, es decir, este mandato se dirige de manera fundamental a los poderes ejecutivo y judicial. Por su parte, el principio de igualdad ante la ley es un mandato dirigido al legislador para que no establezca en los textos legales diferencias no razonables o no justificadas para personas que se encuentran en la misma situación, o para que no regule de la misma manera y de forma injustificada a

\footnotetext{
${ }^{23}$ Laporta, Francisco J., “El principio de igualdad: introducción a su análisis”, cit., pp. 24-25.

${ }^{24}$ Bernal Pulido, Carlos, "El juicio de la igualdad en la jurisprudencia de la Corte Constitucional colombiana” en Vega Gómez, Juan y Corzo Sosa, Edgar (coordinadores), Instrumentos de tutela y justicia constitucional. Memoria del VII Congreso Iberoamericano de Derecho Constitucional, México, IIJ-UNAM, 2002.
} 
personas que se encuentran en circunstancias desiguales ${ }^{25}$.

Esta distinción ha sido reconocida por muchos tribunales constitucionales en el mundo; el Tribunal Constitucional español la ha explicado de la siguiente forma: para el Tribunal, la igualdad ante la ley se viola "cuando la norma distingue de forma irrazonable y arbitraria un supuesto de hecho específico, al que anuda consecuencias jurídicas determinadas. En tal caso, la norma trata de forma distinta situaciones iguales y crea, sin fundamento fáctico suficiente, un supuesto diferente, lo que supone una violación del principio de igualdad”; por su parte, la igualdad en la aplicación de la ley estaría siendo vulnerada, por poner un ejemplo, “cuando un órgano aplicador del derecho -bien de la administración, bien un órgano judicial- interpreta la norma pertinente en un determinado supuesto de manera distinta a como lo ha hecho anteriormente en casos sustancialmente iguales” (sentencia 73/1989).

Sobre este último supuesto, el Tribunal Constitucional ha entendido que el mandato de igualdad puede servir también como parámetro para evaluar la corrección de una sentencia judicial. Para que pueda acreditarse que un juez o un tribunal no han sido respetuosos del principio de igualdad en la aplicación de la ley el Tribunal Constitucional exige que exista identidad del órgano judicial, identidad sustancial de los supuestos que se están juzgando y ausencia de una fundamentación adecuada que justifique un cambio de criterio interpretativo ${ }^{26}$.

La distinción entre estos dos tipos de igualdad es importante para poner de manifiesto que todas las autoridades están sometidas a las disposiciones constitucionales que protegen justamente el principio de igualdad, el cual se proyecta hacia los distintos órganos públicos en momentos diversos y les impone también obligaciones diferentes. En un primer momento, el principio de igualdad tiene incidencia en el diseño de la ley y del resto de normas generales de rango sub-constitucional. En una segunda etapa, la igualdad impone tratos razonables y no discriminatorios a las autoridades encargadas de aplicar esas normas generales.

\section{LA IGUALDAD EN SENTIDO SUSTANCIAL}

Dentro del análisis de los diferentes tipos de normas que contienen, detallan y desarrollan el principio de igualdad deben mencionarse aquellos que regulan mandatos de igualdad sustancial, también llamada igualdad real o de hecho. De acuerdo con este tipo de normas los poderes públicos deben remover los obstáculos que impidan el logro de la igualdad en los hechos, lo que puede llegar a suponer o incluso a exigir la implementación de medidas de acción positiva o de discriminación inversa; para su aplicación conviene identificar previamente a los grupos que, dentro de cada sociedad, se encuentran en situación de vulnerabilidad, respecto de los cuales se tendrán que tomar medidas de promoción y de especial protección.

\footnotetext{
${ }^{25}$ Sobre el tema, entre otros, Díez Picazo, Luis María, “Sobre la igualdad ante la ley” en La democracia constitucional. Estudios en homenaje al profesor Francisco Rubio Llorente, Madrid, CEPC, UCM, Tribunal Constitucional, 2002, tomo I, pp. 469 y ss.

${ }^{26}$ Bilbao Ubillos, Juan María y Rey Martínez, Fernando, "El principio constitucional de igualdad en la jurisprudencia española” en Carbonell, Miguel (compilador), El principio constitucional de igualdad. Lecturas de introducción, México, CNDH, 2003, p. 116 y ss.
} 
La idea de la igualdad sustancial parte de la afirmación de Aristóteles que ya hemos citado en el sentido de que la justicia consiste en tratar igual a los iguales y desigual a los desiguales. Es decir, no sería justo tratar como iguales a quienes no lo son y no lo pueden ser porque carecen de las posibilidades para alcanzar una situación igualitaria. Podríamos suponer que los hombres y las mujeres son, en principio, iguales para el efecto de su tratamiento por la ley; pero si acudimos a las estadísticas comprobaremos que esa igualdad jurídica se materializa en severas desigualdades fácticas, lo cual significa por ejemplo que las mujeres están relegadas en muchos ámbitos, no porque la ley les prohíba ingresar en ellos, sino porque las formas de convivencia social y muchos prejuicios se los impiden. Lo mismo sucede con algunas minorías; es verdad que no hay una ley que impida que las personas de color puedan acudir a las universidades en Estados Unidos, pero todas las evidencias demuestran que su ingreso en ellas es notablemente inferior respecto a las personas de raza blanca.

La cuestión interesante para el derecho constitucional es si por medio de normas jurídicas se pueden y se deben revertir esas desigualdades o si el ordenamiento jurídico se debe limitar a prohibir cualquier forma de discriminación por medio de previsión de igualdad formal. En el fondo, lo que late en este tema es un interrogante más amplio sobre el papel del derecho en las sociedades modernas: ¿el derecho debe servir solamente para lograr la convivencia pacífica de una comunidad o puede ser utilizado también para modelar esa misma sociedad según nuestros ideales de justicia?, es decir, ¿el derecho tiene la capacidad para servir como un motor de transformación social sin por ello dejar de servir a los valores que le dan legitimidad?

Para quienes sostienen la pertinencia de avanzar hacia esquemas de igualdad sustancial o real a través de las normas jurídicas las preguntas anteriores tienen una respuesta clara: el derecho no solamente puede servir como motor del cambio social, sino que de no hacerlo estaría perpetuando el status quo y negando con ello el sentido mismo de la igualdad tal como ha sido entendido por lo menos desde Aristóteles.

Llegados a este punto la cuestión lejos de simplificarse parece complicarse a cada paso. Muy bien. Supongamos que el derecho debe servir no solamente para decirnos que todos somos iguales, sino también para hacernos más iguales. ¿Cómo lograr ese objetivo sin afectar a otros bienes de rango constitucional? ¿cómo lograr la igualdad partiendo de reconocer que no todos somos iguales? ¿si es verdad que no todos somos iguales, qué desigualdades debemos tomar en cuenta para efecto de perseguir por medio de las normas jurídicas una mayor igualación social? En concreto, ¿podemos tomar en cuenta alguno de los rasgos incluidos en el mandato de no discriminación para efecto de corregir desigualdades?, es decir, ¿podemos utilizar el criterio del sexo de una persona o la raza para construir un supuesto normativo que haga más iguales a quienes son mujeres o tienen la piel de $\mathrm{X}$ o $\mathrm{Y}$ color? ¿y si aceptamos esos rasgos como válidos para efectos de un tratamiento normativo diferenciado podemos también aceptar el criterio de las preferencias sexuales o el de las creencias religiosas y crear un sistema de protección especial para los homosexuales o para los practicantes del shintoismo?

Como puede apreciarse no son cuestiones sencillas. Sin embargo, parece que hay al menos dos ideas claras que son difíciles de refutar: la primera que es si defendemos 
que el ordenamiento trate por igual a todos es probable que quienes tengan más recursos acaben disfrutando de un trato igual y quienes tengan menos acaben, de hecho, sufriendo profundas discriminaciones, aunque no estén basadas en los criterios bajo los que la norma permite distinguir entre las personas. La segunda idea es que, aceptando que el mandato de igualdad puede requerir de medidas especiales para corregir desigualdades de hecho, tenemos que crear esquemas que permitan avanzar hacia una mayor igualdad sin destruir las bases mismas de esa igualdad, es decir, sin generar nuevas discriminaciones ${ }^{27}$.

Para intentar lograr lo anterior se han creado diversos esquemas. En las páginas siguientes vamos a detenernos en algunas cuestiones sobre las que la teoría jurídica y social contemporánea ha debatido intensamente en los últimos años.

\subsection{Las acciones positivas.}

Aunque, como acabamos de señalar, la discusión sobre la igualdad sustancial es muy intensa, lo cierto es que no son pocos los ordenamientos constitucionales contemporáneos que contienen mandatos que obligan a los poderes públicos a tomar medidas positivas y acciones diversas para alcanzar una igualdad de ese tipo.

Dentro del género de normas jurídicas que contienen mandatos de igualdad sustancial se pueden identificar al menos dos distintos modelos de preceptos; unos que se podrían llamar de "primera generación” y otros que tal vez puedan ser calificados como de “segunda generación”. Entre los primeros se encuentran, por ejemplo, los artículos 9.2 de la Constitución española o 3.2 de la Constitución italiana ${ }^{28}$. Entre los segundos está el importante y polémico agregado de 1999 al artículo 3 de la Constitución francesa, que ha dado lugar a importantes cambios en la legislación electoral de ese país; el texto en cuestión dispone que "La ley favorece el igual acceso de las mujeres y de los hombres a los mandatos electorales y funciones electivas". Este precepto se complementa con un añadido al artículo 4 de la misma Constitución, de acuerdo con el cual los partidos políticos deben contribuir a la puesta en acción del mandato del artículo 3 dentro de las condiciones que establezca la ley.

Son mandatos de este tipo los que permiten el establecimiento, entre otras medidas, de las llamadas acciones positivas, una de cuyas manifestaciones concretas son las cuotas electorales de género a las que haremos referencia en uno de los apartados siguientes.

La acción positiva puede definirse como "el trato formalmente desigual que basa la diferencia en el tratamiento en la pertenencia a un grupo que comparte la posesión de un rasgo minusvalorado... se caracteriza principalmente por ser medidas

\footnotetext{
${ }^{27}$ Ferrajoli señala que con la igualdad sustancial se intenta que las personas sean de hecho tan iguales como sea posible, partiendo de la base de que de hecho son social y económicamente desiguales; ver Derecho y razón, $5^{\text {a }}$ edición, Madrid, Trotta, 2000, p. 907.

${ }^{28}$ Artículo 9.2 de la Constitución española: “Corresponde a los poderes públicos promover las condiciones para que la libertad y la igualdad del individuo y de los grupos en que se integra sean reales y efectivas; remover los obstáculos que impidan o dificulten su plenitud y facilitar la participación de todos los ciudadanos en la vida política, económica, cultural y social”. Artículo 3 párrafo segundo de la Constitución italiana: “Constituye obligación de la República suprimir los obstáculos de orden económico y social que, limitando de hecho la libertad y la igualdad de los ciudadanos, impiden el pleno desarrollo de la persona humana y la participación efectiva de todos los trabajadores en la organización política, económica y social del país”.
} 
que favorecen a los miembros de un colectivo por su pertenencia al mismo, no por circunstancias individuales"29.

Algunos autores distinguen entre las acciones positivas y las medidas de igualación positiva. Estas medidas se pueden definir como "los tratos formalmente desiguales que tienen como finalidad constitucionalmente admisible la igualdad entre los ciudadanos individualmente considerados y, por ello, basan la diferencia en el trato en la situación de inferioridad del beneficiado, situación de inferioridad que viene

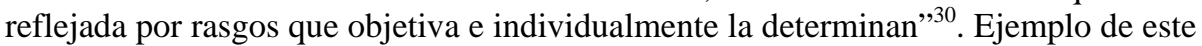
tipo de medidas son las becas, la progresividad del impuesto sobre la renta, los descuentos en el acceso a servicios públicos, los beneficios en prestaciones públicas, etcétera. El objetivo de las acciones positivas es la igualdad real entre los grupos sociales, mientras que el de las medidas de igualación positiva es el de lograr la igualdad real entre los sujetos de los derechos fundamentales, considerados en forma individual.

Dentro de las acciones positivas se puede distinguir entre acciones positivas moderadas y medidas de discriminación inversa ${ }^{31}$. Las primeras buscarían favorecer al valor de la igualdad sustancial a través de medidas de igualación que permitan remover los obstáculos que impiden a los miembros de grupos discriminados llegar a procesos de selección social (escuela, trabajo, acceso a servicios sanitarios, etcétera), en condiciones de igualdad con el resto de las personas. Las segundas son concretamente las cuotas que se reservan a diversos grupos discriminados para alcanzar bienes sociales escasos (lugares en la universidad, puestos públicos, listas electorales, etcétera).

Las acciones positivas moderadas están enfocadas a conseguir objetivos (goals), mientras que las medidas de discriminación inversa tienen metas menos flexibles, expresadas frecuentemente como porcentajes de las cuotas para los bienes sociales que ya se han mencionado.

Al tratar el tema de las acciones positivas Ronald Dworkin formula las dos preguntas más importantes que se deben contestar tanto desde la teoría de la justicia (o desde el ámbito de la filosofía política) como desde la teoría del derecho. Las dos preguntas son: A) ¿las acciones positivas son justas?; y B) ¿las acciones positivas logran sus objetivos (es decir, son eficaces) ? $^{32}$. Para responder a la primera pregunta debemos aportar elementos axiológicos, que nos permitan argumentar que las acciones tienen encaje en una Constitución que protege los derechos fundamentales de todos de la mejor manera posible. La segunda pregunta parte de premisas utilitarias; si las acciones positivas no consiguen su objetivo no serían legítimas ya que pondrían en peligro o al menos en tensión un bien de rango constitucional (la igualdad formal) a cambio de nada. Habrá pues de estar en capacidad de responder a las dos cuestiones planteadas por Dworkin si queremos sostener la legitimidad constitucional de las acciones positivas.

\footnotetext{
${ }^{29}$ Giménez Gluck, David, Una manifestación polémica del principio de igualdad: acciones positivas moderadas y medidas de discriminación inversa, Valencia, Tirant Lo Blanch, 1999, p. 62.

${ }^{30}$ Giménez Gluck, David, Una manifestación polémica del principio de igualdad: acciones positivas moderadas y medidas de discriminación inversa, cit., p. 58.

${ }^{31}$ Idem, pp. 75 y ss. Ver también Rey Martínez, La discriminación por razón de sexo..., cit., pp. 83 y ss.

${ }^{32}$ A contestar estas dos preguntas se dedican los capítulos 11 y 12 de su libro Virtud soberana, cit., pp. 419 y ss.
} 
Sobre los problemas éticos o axiológicos que presentan las acciones afirmativas conviene recordar un párrafo muy ilustrativo de uno de los más brillantes constitucionalistas de los Estados Unidos, que recogía a finales de la década de los años 70 del siglo XX una preocupación muy extendida entre los analistas del tema en los siguientes términos ${ }^{33}$ :

La 'discriminación inversa' en favor de una minoría racial o de otro tipo plantea un difícil problema ético. Si, por una parte, hemos de tener siquiera la oportunidad de curar a nuestra sociedad de la enfermedad del racismo, necesitaremos muchos más miembros de los grupos minoritarios en las profesiones y en los estratos más altos de la sociedad. Y cualquiera que sea el conjunto de razones para ello, no parece probable que esto suceda en el futuro próximo a menos de que tomemos su condición de minorías en cuenta y la ponderemos positivamente cuando asignamos las oportunidades. Pero independientemente del nombre que le demos - preferencia, cuota, búsqueda de la diversidad- el ponderar afirmativamente a los negros, por ejemplo, significa necesariamente que se negará a otros las oportunidades en cuestión por no ser negros de nacimiento. Confieso, por consiguiente, que tengo problemas para comprender el lugar de la indignación moral en cualquiera de los dos lados de este desgarrador dilema moral.

Al estudiar la legitimidad de las acciones positivas en el derecho constitucional de los Estados Unidos Dworkin nos ofrece también una interesante reflexión sobre los alcances que le podemos dar a la cláusula de igual protección (o de igual trato) prevista en la Enmienda Decimocuarta de la Constitución de 1787 o en el artículo 1 de nuestro texto constitucional de 1917. Así por ejemplo, Dworkin afirma que

La cláusula de la igual protección no resulta violada cuando algún grupo ha sido derrotado en una decisión importante de acuerdo a los méritos de su posición o a través de la política, sino cuando la derrota es un efecto de su especial vulnerabilidad al prejuicio, la hostilidad o los estereotipos y su consecuente situación disminuida -su ciudadanía de segunda clase- en la comunidad política. La cláusula mencionada no garantiza a cada ciudadano que vaya a beneficiarse de igual modo con cada decisión política; sólo le garantiza que va a ser tratado como un igual -con igualdad de consideración y respeto- en el proceso político y las deliberaciones que producen dichas consecuencias ${ }^{34}$.

Es decir, según Dworkin debemos atender no solamente a las consecuencias de una ley o de una política pública sobre el igual trato, sino también a las intenciones de quienes las emitieron. Pero intentando ser objetivos, los tribunales deben atender más bien a los resultados que a las intenciones, que en el funcionamiento de los Estados modernos no son siempre fáciles de ser apreciadas.

En Estados Unidos los tribunales han procedido de la siguiente manera al enjuiciar si una ley o una política pública podrían vulnerar la cláusula de la Enmienda Décimocuarta:

${ }^{33}$ Ely, John Hart, Democracia y desconfianza. Una teoría del control constitucional, Bogotá, Siglo del Hombre editores, 1997, pp. 204-205.

${ }^{34}$ Virtud soberana, cit., p. 451. 
Dichos órganos someten todas las decisiones políticas cuestionadas en el terreno de la protección equitativa a una clasificación inicial. Si una decisión conlleva desventajas para lo que la Corte Suprema ha denominado una "clase sospechosa" - una clase, de acuerdo con una famosa definición, que "lleva una carga de discapacidades, o está sujeta a una historia de tratamiento desigual intencional o es relegada a una posición de debilidad política como para dirigir una protección extraordinaria por parte del proceso político mayoritario”-, la decisión debe ser entonces sometida a un "escrutinio estricto". Esto implica que debe ser rechazada por violar la cláusula de la igual protección a menos que pueda demostrarse que las desventajas mencionadas resultan esenciales para proteger algún interés gubernamental "concluyente"*. Pero si aquellos a quienes la ley perjudica no constituyen una clase "sospechosa" -si sólo son miembros de un negocio o una profesión particular determinada o residentes de un área particular y no son diferentes de sus conciudadanos en algún aspecto históricamente asociado con la hostilidad o el prejuicio-, entonces esa ley debe ser sometida sólo a un escrutinio "relajado": es constitucional a menos que pueda demostrarse que no sirve en absoluto a ningún propósito o fin $^{35}$.

Normalmente, el escrutinio estricto es fatal, porque ninguna medida legislativa o administrativa es capaz de superarlo, mientras que el "escrutinio relajado" no es en verdad un escrutinio, ya que a cualquier medida se le puede encontrar una finalidad que la justifique, por nimia que sea ${ }^{36}$.

¿Pueden los jueces aplicar el razonamiento de los niveles de escrutinio a las acciones positivas? Y, en caso afirmativo, ¿de qué manera deben hacerlo? Dworkin rechaza que los niveles de escrutinio sean una buena técnica para el enjuiciamiento constitucional de las acciones positivas ${ }^{37}$, si bien reconoce que en la práctica han sido aplicadas por la Corte Suprema, aunque introduciendo algunos matices. Así por ejemplo, la Corte ha resuelto algunos casos considerando que las acciones afirmativas podían ser sometidas a un "escrutinio intermedio”, según el cual debía justificarse que una medida de discriminación inversa servía a un "interés importante”, pero no a un "interés concluyente"38 . ¿Cuál podría ser un ejemplo de “interés importante”?

\footnotetext{
* Los traductores del libro de Dworkin eligieron el término “interés concluyente” para traducir la expresión en inglés “compeling interest”; quizá no se trate de la mejor traducción.

${ }^{35}$ Virtud soberana, cit., p. 453.

${ }^{36}$ Idem.

${ }^{37}$ Virtud soberana, cit., p. 454.

${ }^{38}$ Virtud soberana, cit., p. 455.

${ }^{39}$ Una idea parecida ha sido recogida por la jurisprudencia mexicana, por ejemplo en las dos siguientes tesis jurisprudenciales:

IGUALDAD. CASOS EN LOS QUE EL JUEZ CONSTITUCIONAL DEBE HACER UN ESCRUTINIO ESTRICTO DE LAS CLASIFICACIONES LEGISLATIVAS (INTERPRETACIÓN DEL ARTÍCULO 1o. DE LA CONSTITUCIÓN POLÍTICA DE LOS ESTADOS UNIDOS MEXICANOS). La igualdad es un principio y un derecho de carácter fundamentalmente adjetivo que se predica siempre de algo, y este referente es relevante al momento de realizar el control de constitucionalidad de las leyes, porque la Norma Fundamental permite que en algunos ámbitos el legislador tenga más amplitud para desarrollar su labor normativa, mientras que en otros el Juez debe ser más exigente a la hora de determinar si aquél ha respetado las exigencias del principio de igualdad. El artículo 1o. de la Constitución Federal establece varios casos en los que procede dicho escrutinio estricto. Así, su primer párrafo proclama que todo
} 
individuo debe gozar de las garantías que ella otorga, las cuales no pueden restringirse ni suspenderse sino en los casos y con las condiciones que la misma establece, lo que evidencia la voluntad constitucional de asegurar en los más amplios términos el goce de los derechos fundamentales, y de que las limitaciones a ellos sean concebidas restrictivamente, de conformidad con el carácter excepcional que la Constitución les atribuye. Por ello, siempre que la acción clasificadora del legislador incida en los derechos fundamentales garantizados constitucionalmente, será necesario aplicar con especial intensidad las exigencias derivadas del principio de igualdad y no discriminación. Por su parte, el párrafo tercero del citado precepto constitucional muestra la voluntad de extender la garantía de igualdad a ámbitos que trascienden el campo delimitado por el respeto a los derechos fundamentales explícitamente otorgados por la Constitución, al prohibir al legislador que en el desarrollo general de su labor incurra en discriminación por una serie de motivos enumerados (origen étnico o nacional, género, edad, capacidades diferentes, condición social, condiciones de salud, religión, opiniones, preferencias, estado civil) o en cualquier otro que atente contra la dignidad humana y tenga por objeto anular o menoscabar los derechos y libertades de las personas. La intención constitucional es, por lo tanto, extender las garantías implícitas en el principio de igualdad al ámbito de las acciones legislativas que tienen un impacto significativo en la libertad y la dignidad de las personas, así como al de aquellas que se articulan en torno al uso de una serie de criterios clasificatorios mencionados en el referido tercer párrafo, sin que ello implique que al legislador le esté vedado absolutamente el uso de dichas categorías en el desarrollo de su labor normativa, sino que debe ser especialmente cuidadoso al hacerlo. En esos casos, el Juez constitucional deberá someter la labor del legislador a un escrutinio especialmente cuidadoso desde el punto de vista del respeto a la garantía de igualdad. Clave: $1^{\text {a }}$, Núm.: CXXXIII/2004. Amparo directo en revisión 988/2004. 29 de septiembre de 2004. Unanimidad de cuatro votos. Ponente: José Ramón Cossío Díaz. Secretaria: Rosalba Rodríguez Mireles.

IGUALDAD. CRITERIOS PARA DETERMINAR SI EL LEGISLADOR RESPETA ESE PRINCIPIO CONSTITUCIONAL. La igualdad en nuestro texto constitucional constituye un principio complejo que no sólo otorga a las personas la garantía de que serán iguales ante la ley (en su condición de destinatarios de las normas y de usuarios del sistema de administración de justicia), sino también en la ley (en relación con su contenido). El principio de igualdad debe entenderse como la exigencia constitucional de tratar igual a los iguales y desigual a los desiguales, de ahí que en algunas ocasiones hacer distinciones estará vedado, mientras que en otras estará permitido o, incluso, constitucionalmente exigido. En ese tenor, cuando la Suprema Corte de Justicia de la Nación conoce de un caso en el cual la ley distingue entre dos o varios hechos, sucesos, personas o colectivos, debe analizar si dicha distinción descansa en una base objetiva y razonable o si, por el contrario, constituye una discriminación constitucionalmente vedada. Para ello es necesario determinar, en primer lugar, si la distinción legislativa obedece a una finalidad objetiva y constitucionalmente válida: el legislador no puede introducir tratos desiguales de manera arbitraria, sino que debe hacerlo con el fin de avanzar en la consecución de objetivos admisibles dentro de los límites marcados por las previsiones constitucionales, o expresamente incluidos en ellas. En segundo lugar, es necesario examinar la racionalidad o adecuación de la distinción hecha por el legislador: es necesario que la introducción de una distinción constituya un medio apto para conducir al fin u objetivo que el legislador quiere alcanzar, es decir, que exista una relación de instrumentalidad entre la medida clasificatoria y el fin pretendido. En tercer lugar, debe cumplirse con el requisito de la proporcionalidad: el legislador no puede tratar de alcanzar objetivos constitucionalmente legítimos de un modo abiertamente desproporcional, de manera que el juzgador debe determinar si la distinción legislativa se encuentra dentro del abanico de tratamientos que pueden considerarse proporcionales, habida cuenta de la situación de hecho, la finalidad de la ley y los bienes y derechos constitucionales afectados por ella; la persecución de un objetivo constitucional no puede hacerse a costa de una afectación innecesaria o desmedida de otros bienes y derechos constitucionalmente protegidos. Por último, es de gran importancia determinar en cada caso respecto de qué se está predicando con la igualdad, porque esta última constituye un principio y un derecho de carácter fundamentalmente adjetivo que se predica siempre de algo, y este referente es relevante al momento de realizar el control de constitucionalidad de las leyes, porque la Norma Fundamental permite que en algunos ámbitos el legislador tenga más amplitud para desarrollar su labor normativa, mientras que en otros insta al Juez a ser especialmente exigente cuando deba determinar si el legislador ha respetado las exigencias derivadas del principio mencionado. Clave: $1^{\mathrm{a}}$, Núm.: CXXXII/2004. Amparo directo en revisión 988/2004. 29 de septiembre de 2004. Unanimidad de cuatro votos. Ponente: José Ramón Cossío Díaz. Secretaria: Rosalba Rodríguez Mireles. 
Dworkin dirige la mayor parte de su exposición a justificar las medidas de acción positiva utilizadas para el ingreso de estudiantes de raza negra en las universidades ${ }^{40}$. Para nuestro autor, el interés importante que justificaría esas medidas estaría, en primer lugar, en la diversidad estudiantil que debe existir en los campus universitarios, de modo que los estudiantes tengan como compañeros a personas que reflejen de alguna manera el pluralismo de la sociedad norteamericana ${ }^{41}$; pero también existiría ese interés importante en un sentido más institucional: se trataría de corregir la ausencia de personas de raza negra en posiciones importantes en el gobierno, la política, los negocios y las profesiones, corrección que solamente se puede realizar si esas personas ingresan en las universidades. La existencia de ese interés vendría acreditada por una cuestión de hecho: "Uno de los problemas más graves de la sociedad norteamericana -dice Dworkin- es la estratificación racial de facto que ha excluido de forma considerable a los negros y a los miembros de otras minorías de los puestos más altos del poder, la riqueza y el prestigio; la discriminación racial del pasado, así como el círculo vicioso que priva a los niños negros de contar con líderes de éxito de dicha raza como referentes para imitar, ha contribuido sustancialmente a esa estratificación"42.

El debate norteamericano sobre el tema se desarrolló en los términos que, de forma muy resumida, acabamos de plantear. Pero la justificación de las acciones positivas en otros contextos constitucionales pueden darse por vías distintas. Siguiendo la exposición de Giménez Gluck, las acciones positivas deben reunir los tres siguientes requisitos para poder ser aceptadas dentro de un Estado constitucional ${ }^{43}$ :

A) Deben ser temporales, es decir, se mantienen en vigor mientras subsista la situación de discriminación que las originó. Una vez superada esa situación de inferioridad, infravaloración o, en general, de sujeción, las acciones pierden su sentido y su legitimidad constitucional.

\footnotetext{
${ }^{40}$ Este es un tema que ha interesado ha Dworkin desde hace muchos años y al que había dedicado uno de los capítulos de su libro Los derechos en serio, Barcelona, Ariel, 1984, capítulo 9, pp. 327 y ss.

${ }^{41}$ Dworkin apunta: "las universidades norteamericanas se han propuesto conseguir que las clases sean diversas en varias formas. Esas instituciones han supuesto, de modo plausible, que los estudiantes estarán mejor equipados para la vida comercial y profesional, así como mejor preparados para actuar como buenos ciudadanos en una democracia pluralista, si han trabajado e interactuado con compañeros de diferente contexto geográfico, clase económica, religión, cultura y, sobre todo ahora, raza”, Virtud soberana, cit., p. 441.

${ }^{42}$ Virtud soberana, cit., p. 467.

${ }^{43}$ Giménez Gluck, Una manifestación polémica del principio de igualdad: acciones positivas moderadas y medidas de discriminación inversa, cit., pp. 37 y ss. Ver también la exposición de Kemelmajer, quien señala que para considerar legítima constitucionalmente una medida de discriminación inversa se debe probar: a) la existencia de un obstáculo de hecho que se opone a la realización de la igualdad de oportunidades; b) motivación suficiente y prueba sobre el obstáculo de hecho que se intenta sobrepasar; c) la proporcionalidad de la medida, acreditando que es el medio menos agresivo para lograr el fin perseguido; d) transitoriedad y reversibilidad de la medida; y e) incidencia en las causas de la discriminación original y no solamente en el resultado; Kemelmajer de Carlucci, Aída, "Las acciones positivas” en Carbonell, Miguel (compilador), El principio constitucional de igualdad. Lecturas de introducción, cit., pp. 257-260.
} 
B) Los rasgos que las originan deben ser transparentes e inmodificables (es decir, no deben depender, o al menos no en todos los casos, de la voluntad de las personas de que se trata).

C) La finalidad debe ser proporcional; el juicio de proporcionalidad es uno de los más arduos de realizar por los órganos de la jurisdicción constitucional y uno de los que permiten dictar sentencias más decisionistas a los jueces ${ }^{44}$. ¿Cuándo una medida de discriminación inversa es proporcional?, ¿en qué momento deja de serlo y se convierte en una pura y simple discriminación, violando de esa forma el texto constitucional? De acuerdo con la Corte Constitucional de Colombia, que adopta su criterio con base en la jurisprudencia del Tribunal Europeo de Derechos Humanos y de los tribunales constitucionales de España y Alemania, "El concepto de proporcionalidad comprende tres conceptos parciales: la adecuación de los medios escogidos para la consecución del fin perseguido, la necesidad de la utilización de esos medios para el logro del fin (esto es, que no exista otro medio que pueda conducir al fin y que sacrifique en menor medida los principios constitucionales afectados por el uso de estos medios), y la proporcionalidad en sentido estricto entre medios y fin, es decir, que el principio satisfecho por el logro de este fin no sacrifique principios constitucionalmente más importantes ${ }^{\text {45 }}$.

La utilización de las medidas de discriminación inversa (las cuotas, por ejemplo) debe ser subsidiaria con respecto a otros mecanismos que también tienden a lograr la igualdad real; es decir, deben ser utilizadas como un último recurso y siempre que no sea posible lograr el mismo efecto por medio de otras medidas menos extremas $^{46}$. Al momento de enjuiciar la constitucionalidad de una norma o una medida que incorpore acciones positivas, este aspecto puede verificarse mediante el "juicio de indispensabilidad"

Por lo que hace a la utilidad de las acciones positivas, es decir, a la segunda de las preguntas planteadas por Dworkin, la evidencia de los resultados de las acciones positivas solamente se puede recabar en aquellos países que llevan un periodo de tiempo más o menos largo aplicándolas. No es el caso de México, en donde, como lo explicaremos con detalle más adelante, apenas se están comenzando a implementar las primeras acciones positivas, en forma de cuotas electorales de género (puestas en funcionamiento por vez primera en las elecciones federales de julio del 2003).

Dworkin demuestra la utilidad de las acciones positivas con base en un estudio realizado por William G. Bowen y Derek Bok -quienes fueron rectores de Princeton y Harvard- en el que se analiza una enorme base de datos en la que se da seguimiento a estudiantes norteamericanos en la segunda mitad del siglo XX. A partir de ese estudio, Dworkin va deshaciendo las principales objeciones que se suelen esgrimir en contra de las cuotas en favor de los estudiantes negros en las universidades.

\footnotetext{
${ }^{44}$ Sobre el principio de proporcionalidad el mejor texto que se ha publicado en español es, hasta donde tengo información, el de Bernal Pulido, Carlos, El principio de proporcionalidad y los derechos fundamentales, Madrid, CEPC, 2003.

${ }^{45}$ Sentencia C-022 de 1996 citada por Bernal Pulido, “El juicio de la igualdad...”, cit., p. 58, nota al pie 27.

${ }^{46}$ Rey Martínez, La discriminación por razón de sexo..., cit., p. 86.

${ }^{47}$ Bernal Pulido, "El juicio de la igualdad...”, cit., p. 67.
} 
Uno de esos prejuicios consiste en sostener que el sistema de cuotas permite la admisión de pésimos estudiantes; los resultados demuestran lo contrario, ya que los estudiantes negros admitidos por el sistema de cuotas en 1989 presentan mejores resultados que el total de estudiantes admitidos en 1951, además de que los estudiantes admitidos por el sistema de cuotas que han llegado a graduarse han tenido un éxito profesional bastante apreciable y, en todo caso, semejante al de los graduados de raza blanca $^{48}$.

Otro prejuicio frecuente consiste en pensar que los estudiantes negros admitidos por el sistema de cuotas "desperdician” la oportunidad que se les ofrece y que estarían mejor en instituciones menos exigentes. Las evidencias empíricas que suministra el estudio de Bowen y Bok parecen sugerir lo contrario: la mayoría de estudiantes negros dijeron sentirse muy satisfechos con su experiencia universitaria ${ }^{49}$.

Otros prejuicios sostienen que las cuotas crean hostilidad en los campus universitarios, al instalar en ellos a personas que no tienen los méritos suficientes con independencia de su raza o bien que con las cuotas se insulta a las personas de raza negras al suponer que necesitan una ayuda para poder acceder en igualdad de condiciones con los blancos a las universidades. Uno a uno, el estudio de Bowen y Bok hace caer esos mitos.

Los datos permiten concluir a Dworkin que el sistema de cuotas universitarias ha sido un éxito en Estados Unidos y que no habría razón para abandonarlo; es más, se calcula que si los programas universitarios de cuotas para personas de raza negra se abandonaran, el número de estudiantes negros en las aulas de las universidades más prestigiosas y exigentes bajaría entre un 50 y un $75 \%{ }^{50}$. Para Dworkin, "De acuerdo con la que constituye la mejor evidencia disponible, por tanto, la discriminación positiva no resulta contraproducente. Al contrario, parece tener un éxito extraordinario. Tampoco es injusta, ya que no viola ningún derecho individual ni compromete ningún principio moral”,

Antes de terminar esta introducción al tema de la igualdad sustancial y a las acciones afirmativas, conviene mencionar que, como consecuencia de su discutible encaje en el constitucionalismo moderno y de no pocos prejuicios y malos entendidos, existen en algunas Constituciones prohibiciones expresas para tales acciones. Jon Elster advierte que la inclusión de esas prohibiciones estuvo fundada en profundos prejuicios de las mayorías constituyentes hacia las minorías étnicas que habitan en Bulgaria, Rumania y Eslovaquia. Elster explica en un párrafo que vale la pena transcribir esta problemática $^{52}$ :

Todas las Constituciones de la región (se refiere Elster a Europa Central y Oriental) incluyen cláusulas que prohíben la discriminación (negativa) por

\footnotetext{
${ }^{48}$ Virtud soberana, cit., p. 426-427.

${ }^{49}$ Virtud soberana, cit., p. 430.

${ }^{50}$ Virtud soberana, cit., p. 436.

${ }^{51}$ Virtud soberana, cit., p. 446.

52 Elster, Jon, “La deliberación y los procesos de creación constitucional” en Elster, Jon (compilador), La democracia deliberativa, Barcelona, Gedisa, 2000, p. 136.
} 
motivos de raza, nacionalidad, origen étnico, sexo, religión y muchos otros motivos similares. Pero tres de ellas -las de Bulgaria, Rumania y Eslovaquiacontienen también prohibiciones explícitas respecto de la discriminación inversa o positiva, es decir la acción afirmativa. En el documento rumano la prohibición sólo abarca la discriminación inversa por motivos étnicos. Bulgaria y Eslovaquia trataron al menos de satisfacer la restricción de imperfección al extender el impedimento de la discriminación positiva a todos los criterios que se enumeran en las prohibiciones sobre discriminación negativa. Y sin embargo también en estos países las cláusulas se deben a los prejuicios de una mayoría étnica en la asamblea constituyente contra varias minorías. Los sesgos contra las minorías étnicas hubieran sido aún más fuertes si en los procesos de elaboración no hubiesen intervenido delegados del Consejo de Europa. El primer borrador de la Constitución rumana, por ejemplo, contenía una prohibición aparentemente imparcial de los partidos de base étnica que estaba directamente dirigida contra la numerosa minoría húngara.

Hay que mencionar que, aunque no es una regla seguida de forma unánime por todas las jurisdicciones constitucionales, en el caso de los Estados Unidos su Suprema Corte ha admitido en muchas de sus sentencias la constitucionalidad de las medidas de acción positiva, a pesar de que en su texto constitucional no aparece ninguna cláusula de igualdad material ${ }^{53}$. El estudio detenido de la jurisprudencia norteamericana sobre el tema excede con creces el propósito de este ensayo; de todas formas, recomiendo que el lector que quiera profundizar en la cuestión tome en cuenta la jurisprudencia norteamericana, que es muy iluminadora, en este como en tantos otros aspectos ${ }^{54}$.

De distinta manera han sido recibidas las acciones positivas en Francia y en Italia. En ambos casos, como se menciona más adelante, el Consejo Constitucional y la Corte Costituzionale han declarado la inconstitucionalidad de leyes que establecían cuotas electorales en favor de las mujeres (lo cual ha llevado, en el caso de Francia, a introducir una reforma constitucional para permitir las "políticas de paridad" en materia electoral).

También en el ámbito de la Unión Europea el Tribunal Europeo de Derechos Humanos ha emitido importantes decisiones sobre las acciones positivas, que han generado intensos debates sobre el sentido de esas acciones y sobre sus posibilidades de generar consecuencias deseables en el plano del principio de igualdad ${ }^{55}$. Sin embargo, a pesar de que la jurisprudencia europea pudiera haberse mostrado vacilante en algunos casos, a partir de la entrada en vigor de la Carta Europea de Derechos Fundamentales la pertinencia de las cuotas electorales parece admitida; en efecto, el artículo 23 de la Carta dispone que:

\footnotetext{
${ }^{53}$ Giménez Gluck, Una manifestación polémica del principio de igualdad: acciones positivas moderadas y medidas de discriminación inversa, cit., p. 47.

${ }^{54}$ Para un primer acercamiento a los casos más emblemáticos, Kemelmajer, "Las acciones positivas”, cit., pp. 261 y ss.

${ }^{55}$ Las etapas centrales de la jurisprudencia europea sobre las acciones positivas han estado marcadas por las decisiones Kalanke y Marshall; sobre el tema, Martín Vida, María Ángeles, Fundamento y límites constitucionales de las medidas de acción positiva, Madrid, Civitas, 2002, pp. 71 y ss. y Elósegui Itxaso, María, Las acciones positivas para la igualdad de oportunidades laborales entre hombres y mujeres, Madrid, CEPC, 2003, pp. 119 y ss.
} 
"La igualdad entre hombres y mujeres será garantizada en todos los ámbitos, inclusive en materia de empleo, trabajo y retribución.

El principio de igualdad no impide el mantenimiento o la adopción de medidas que ofrezcan ventajas concretas en favor del sexo menos representado”.

A partir de ese precepto se puede sostener que el principio de igualdad de trato no impedirá a ningún Estado miembro mantener o adoptar medidas de acción positiva, destinadas a facilitar al sexo menos representado el ejercicio de actividades profesionales, incluyendo aquellas que tienen que ver con la representación política.

Como se puede ver, los debates en torno a las acciones positivas han estado presentes en muchos contextos del constitucionalismo contemporáneo. Prácticamente en ningún país se han podido introducir sin que hayan sido llevadas ante la correspondiente jurisdicción constitucional. Los tribunales han realizado una gran tarea interpretativa y también, hay que decirlo, creadora en esta materia. En la mayor parte de los casos han asumido actitudes progresistas y han construido argumentaciones jurídicas que, apoyándose de forma más o menos explícita en el marco constitucional, han permitido sostener la legitimidad de las acciones positivas, aunque no sin serios reparos por algunos de sus miembros o por sectores importantes de la academia.

\subsection{Las cuotas electorales de género.}

Las cuotas electorales por razón de género son una especie dentro del concepto más amplio de las acciones afirmativas o acciones positivas. Tales cuotas son la reserva que hace normalmente la ley electoral y excepcionalmente la Constitución para que ningún género pueda tener más de un determinado porcentaje de representantes en los órganos legislativos. Para algunos autores, las cuotas electorales de género forman parte de las medidas de "discriminación inversa", que a su vez serían una variedad específica de las acciones positivas ya mencionadas ${ }^{56}$.

Así por ejemplo, se puede establecer una representación asegurada mínima para cada género de un 30\% de escaños, al prohibir que un sólo género tenga más del 70\% de los lugares disponibles; a este tipo de cuota de género se le puede llamar de "representación umbral", en tanto que no registra con exactitud el porcentaje de hombres y mujeres que existen -normalmente- en las sociedades contemporáneas, sino que, de manera más simple, se limita a asegurar para cada género un umbral mínimo de representación. El Comité para la Eliminación de la Discriminación contra la Mujer afirma que "Las investigaciones realizadas demuestran que si su participación (se refiere a las mujeres, MC) alcanza entre el 30 y el 35\% (que por lo general se califica de 'masa crítica'), entonces puede tener verdaderas repercusiones en el estilo político y en el contenido de las decisiones y la renovación de la vida política" ${ }^{27}$.

\footnotetext{
${ }^{56}$ Rey Martínez, La discriminación por razón de sexo..., cit., pp. 84-85.

${ }^{57}$ Recomendación General número 23, adoptada en su $16^{\circ}$ periodo de sesiones, en el año 1997, párrafo 16; consultable en Carbonell, Miguel, Moguel, Sandra y Pérez Portilla, Karla (compiladores), Derecho Internacional de los Derechos Humanos. Textos Básicos, 2ª edición, México, Porrúa, UNAM, CNDH, 2003, tomo I, pp. 675 y ss.
} 
Distinto es el caso de las cuotas que establecen un 50\% de escaños para cada género; en este caso se trata de un caso de las llamadas "cuotas duras”, que más que pretender una "representación umbral”, buscan la identidad de los géneros en la repartición de escaños, al establecer una medida lo más parecida posible al porcentaje efectivo de población de hombres y mujeres.

Las cuotas electorales de género surgen a partir de la constatación del bajo índice de mujeres que acceden a cargos públicos representativos. El promedio mundial de parlamentarias en el mundo ronda el 12\%; en Europa se ubica sobre el 15\%, pero en los países árabes apenas es significativo. En México dicho porcentaje alcanzó el 16\% en la LVII Legislatura del Congreso de la Unión (1997-2000). Es en este contexto histórico y político concreto en el que surge la discusión sobre las cuotas de género, las cuales sin duda alguna forman parte de la agenda pública de muchos países, incluyendo desde luego a México ${ }^{58}$.

\subsection{Las razones a favor y en contra de las cuotas electorales de género.}

Las cuotas electorales de género, como en general las acciones afirmativas, han producido un debate muy intenso en la teoría constitucional de los últimos años. Los argumentos a favor y en contra de las cuotas parecen irreductibles y los distintos puntos de vista mantienen posiciones diametralmente opuestas.

Los argumentos que con mayor frecuencia se suelen esgrimir contra las cuotas electorales de género son los siguientes ${ }^{59}$ :

a) Las cuotas violan el principio de igualdad. Los críticos de las cuotas consideran que vulneran el principio de igualdad al no respetar las mismas oportunidades de acceso a puestos representativos para los hombres y las mujeres; para este punto de vista, todos los seres humanos deberían ser tratados de la misma forma y la distribución de recursos que implicaran una visión de la justicia social se debería realizar sin atender a cuestiones de género. La respuesta para esta objeción es que el principio de igualdad no puede considerarse como simetría absoluta y que la idea de una igualdad puramente formal, que no atendiera a las discriminaciones que de hecho existen en nuestras sociedades, acabaría conculcando el objetivo de alcanzar una sociedad justa. Lo cierto, además, es que con las cuotas se intenta reparar una probabilidad objetiva que pesa en contra de las mujeres, de acuerdo con la cual -según lo demuestran las estadísticas- la posibilidad real que tienen de acceder a cargos representativos es notablemente menor que la que tienen los hombres; como afirma Fernando Rey Martínez "La discriminación sufrida por las mujeres es la más antigua y persistente en el tiempo, la más extendida en el espacio, la que más formas ha revestido (desde la simple y brutal violencia, hasta los más sutiles comportamientos falsamente protectores) y la más primaria, porque siempre se añade a todas las demás”60. En este contexto, se puede concluir que las cuotas, más que vulnerar el principio de igualdad,

${ }^{58}$ Cfr. Ruiz Miguel, Alfonso, “La representación democrática de las mujeres” en Carbonell, Miguel (compilador), El principio de igualdad. Lecturas de introducción, México, CNDH, 2003, pp. 283 y ss.

${ }^{59}$ Sigo la exposición de Aguiar, Fernando, “A favor de las cuotas femeninas”, Claves de razón práctica, Madrid, número 116, octubre de 2001.

${ }^{60}$ El derecho fundamental a no ser discriminado por razón de sexo, cit., p. 1. 
en realidad lo afianzan, en la medida en que lo hacen real, ya que impiden una consolidada y permanente discriminación por razón de sexo en contra de las mujeres.

b) Las cuotas no son neutrales y usan un criterio prohibido para diferenciar entre las personas, como lo es el sexo. Esta crítica parte del supuesto de que el derecho y las actividades estatales deben ser neutrales con respecto a algunas características de las personas, como lo pueden ser el sexo, la raza, el origen étnico o nacional, entre otros. La realidad, sin embargo, es que esa neutralidad no existe en la práctica y que los grupos vulnerables o discriminados lo son en buena medida porque no existen incentivos sociales o institucionales que les ofrezcan competir en igualdad de oportunidades con otras personas. Además, las sociedades actuales no son neutrales con relación al género, entendiendo por tal el rol que socialmente se asigna a los hombres y a las mujeres; de esta forma, las mujeres desempeñan roles asociados a la vida privada (cuidado de niños y ancianos, mantenimiento del hogar, etcétera) y los hombres asumen roles en la vida pública (el tema de los roles sociales para efectos de la discriminación por razón de sexo ha sido abordado en el caso Stanton $v$. Stanton fallado por la Corte Suprema de los Estados Unidos en 1975 y ha vuelto aparecer en los casos Craig v. Boren de 1976, Califano v. Wescott de 1979 y Orr v. Orr del mismo año, entre otros). Esta separación de ámbitos de actuación ha supuesto para las mujeres una relegación importante en el campo político, que es justamente lo que tratan de evitar las cuotas electorales. Se podría decir que tal vez las cuotas no son neutrales con respecto al sexo, pero sí respecto al género.

c) Las cuotas son paternalistas. Los críticos de las cuotas afirman que se trata de medidas que consideran a las mujeres como seres indefensos o como menores de edad, que necesitan de la ayuda del ordenamiento jurídico para poder competir con los hombres. En realidad, sucede aproximadamente lo contrario, es decir, porque se considera que las mujeres son igual o más capaces que los hombres para desempeñar cualquier cargo público es por lo que se crean las cuotas, que como se dijo, tienden a disminuir una probabilidad objetiva que opera actualmente contra las mujeres. Las cuotas no se crean porque se piense que las mujeres tienen menos méritos, sino porque las relaciones de poder realmente existentes en nuestras sociedades les impiden aplicar esos méritos en las instituciones representativas.

d) Las cuotas no respetan los criterios de mérito. Se afirma por sus críticos que las cuotas no toman en cuenta el mérito de las personas, sino simplemente su sexo a la hora de distribuir las posibilidades de acceder a cargos públicos electivos. La respuesta a esta objeción es que el mérito, siendo sin duda importante, no puede ser el único criterio para la distribución de beneficios sociales. Puede suceder incluso que el mérito sea un criterio injusto si la situación de partida de dos personas o de dos grupos no es equitativa. A la crítica del mérito se suele acompañar el argumento de que las mujeres ya han logrado avanzar mucho en los distintos ámbitos públicos y que es solamente una cuestión de tiempo para que tengan mayor presencia en los parlamentos y cámaras legislativas; en realidad, los datos demuestran que incluso en sociedades en donde la emancipación de las mujeres se realizó hace muchos años, los cambios siguen sin producirse y la diferencia entre hombres y mujeres sigue siendo muy importante (Francia es el mejor ejemplo). 
Por otro lado, es importante señalar que en materia política los méritos son más difícilmente medibles que en otros campos, pues no hay criterios objetivos que nos puedan indicar si una persona será o no un buen representante popular. Además, si el mérito ha sido hasta ahora el criterio con el que se han integrado los órganos públicos, habría que empezar a cuestionarlo a la vista de los pobres resultados que ha generado y del desencanto que la gente tiene sobre sus representantes populares. La evaluación de los méritos que actualmente hacen nuestras sociedades puede y debe ser cuestionada, pues en muchos aspectos es obvio que no está dando buenos resultados. En relación al criterio de mérito, Elena Beltrán afirma que "Es difícil la defensa, desde un punto de vista moral, de la idea de que alguien merece una posición particular porque está cualificado desde un punto de vista objetivo, si pensamos en el mérito como una construcción social que refleja una serie de factores sobre los cuales el individuo no tiene control, como el talento, el entorno familiar, la educación recibida, los recursos económicos o la socialización en los roles de género" ${ }^{\text {.61 }}$.

La justificación de las cuotas electorales de género procede, según Alfonso Ruiz Miguel, de dos tipos de razones: “en cuanto al fin, las cuotas pretenden una sociedad más igualitaria en la que la pertenencia a la categoría de los hombres o de las mujeres sea irrelevante para el reparto de los papeles públicos y privados, un proceso que se está mostrando muy lento y en buena parte reacio a producirse por mera maduración; en cuanto al medio, facilitar el acceso a puestos socialmente importantes puede ser un instrumento eficaz para lograr ese fin, si no de manera directa y completa, sí al menos como forma de simbolización de la posibilidad de romper el techo de cristal que obstruye a las mujeres formar parte de la inmensa mayoría de los centros de decisión... ofreciendo nuevos modelos de rol más igualitarios para las generaciones más jóvenes"62.

Sobre la justificación de las cuotas, Ferrajoli defiende el hecho de que "puede perfectamente disponerse que a cada uno de los dos géneros, masculino y femenino, se reserve una cuota de los candidatos, o, mejor aun, de los elegidos, o también de los puestos de trabajo, de las funciones directivas y similares”63.

El mismo Ferrajoli apunta, como conclusión del tema sobre la necesidad de introducir medidas de discriminación positiva para proteger la igualdad efectiva de las mujeres (“garantías sexuadas”, las llama), lo siguiente:

Es obvio que ningún mecanismo jurídico podrá por sí solo garantizar la igualdad de hecho entre los dos sexos, por mucho que pueda ser repensado y reformulado en función de la valorización de la diferencia. La igualdad, no solo entre los sexos, es siempre una utopía jurídica, que continuará siendo violada mientras subsistan las razones sociales, económicas y culturales que siempre sustentan el dominio masculino. Pero esto no quita nada de su valor normativo. De otro modo, sería como decir que el habeas corpus no tiene

${ }^{61}$ Beltrán, Elena et al., Feminismos. Debates teóricos contemporáneos, Madrid, Alianza Editorial, 2001, p. 236.

${ }^{62}$ Ruiz Miguel, Alfonso, "Paridad electoral y cuotas femeninas”, Claves de razón práctica, número 94, Madrid, julio-agosto de 1999, p. 48.

${ }^{63}$ Derechos y garantías. La ley del más débil, Madrid, Trotta, 1999, p. 89. 
ningún valor porque a menudo, de hecho, la policía practica detenciones arbitrarias. El verdadero problema, que exige invención e imaginación jurídica, es la elaboración de una garantía de la diferencia que sirva de hecho para garantizar la igualdad $^{64}$.

Por lo que hace al derecho comparado se puede ver que, por ejemplo, la Corte Constitucional italiana y el Consejo Constitucional francés se han pronunciado por la inconstitucionalidad de las cuotas cuando las leyes electorales que las preveían fueron impugnadas; en el caso francés, se tuvo incluso que reformar la Constitución de 1958 para poder darles cobertura constitucional. Recientemente, algunas comunidades autónomas españolas también han introducido cuotas de género en sus leyes electorales, las cuales han sido recurridas ante el Tribunal Constitucional.

En América Latina, las cuotas han sido consideradas como constitucionales al menos por la Suprema Corte de Justicia de México y por la Corte Constitucional de Colombia. Esta última sostuvo tres argumentos en favor de las cuotas que vale la pena consignar, toda vez que refuerzan algunos de los que ya se han mencionado: A) A pesar de existir un claro equilibrio entre la población femenina y la masculina calificada para acceder a los más altos niveles decisorios, tal equilibrio no se refleja en la efectiva representación de uno y otro en dichos niveles; B) Que la precaria representación de la mujer obedece a un criterio irracional de discriminación, más que a supuestos factores de inferioridad natural o de formación cultural y académica, lo demuestra de modo contundente el hecho de que en la carrera administrativa, cuyos cargos se proveen por el sistema de méritos, la representación de la mujer llega incluso a sobrepasar a la del hombre; C) Es necesario remover los obstáculos presentes que impiden la participación de la mujer con medidas que produzcan un doble efecto: uno inmediato, consistente en paliar la sub-representación; y otro a más largo plazo, que incida en la transformación de la mentalidad, incompatible con los propósitos trazados por una Constitución igualitaria y democrática. Hay que recordar que las cuotas fueron establecidas en Colombia por mandato de la Ley 581 de 2000.

\subsection{Las cuotas y el derecho internacional de los derechos humanos.}

En el ámbito internacional, el Comité de Derechos Humanos de la ONU, en su Observación General número 18 (sobre no discriminación, adoptada en su $37^{\circ}$ periodo de sesiones, 1989$)^{65}$ señala que "el principio de igualdad exige algunas veces a los Estados Partes adoptar disposiciones positivas para reducir o eliminar las condiciones que originan o facilitan que se perpetúe la discriminación prohibida por el Pacto. Por ejemplo, en un Estado en el que la situación general de un cierto sector de su población impide u obstaculiza el disfrute de los derechos humanos por parte de esa población, el Estado debería adoptar disposiciones especiales para poner remedio a esa situación. Las medidas de ese carácter pueden llegar hasta otorgar, durante un tiempo, al sector de la población de que se trate un cierto trato preferencial en cuestiones concretas en comparación con el resto de la población. Sin embargo, en

${ }^{64}$ Idem, p. 92.

${ }^{65}$ Consultable en Carbonell, Moguel y Pérez Portilla, Derecho Internacional de los Derechos Humanos. Textos básicos, cit., tomo I, pp. 422 y ss. 
cuanto son necesarias para corregir la discriminación de hecho, esas medidas son una diferenciación legítima con arreglo al Pacto” (párrafo 10).

En sentido parecido, el Comité para la Eliminación de la Discriminación contra la Mujer de la ONU, en su Recomendación General número 5 (sobre medidas especiales temporales, adoptada en su $7^{\circ}$ periodo de sesiones, 1988) ${ }^{66}$, recomienda que los Estados Partes de la Convención sobre la Eliminación de Todas las Formas de Discriminación contra la Mujer (entre los que se encuentra México) "hagan mayor uso de medidas especiales de carácter temporal como la acción positiva, el trato preferencial o los sistemas de cupos para que la mujer se integre en la educación, la economía, la política y el empleo”.

Esta recomendación encuentra sustento en el artículo 4.1 de la propia Convención, que dispone lo siguiente: "La adopción por los Estados Partes de medidas especiales de carácter temporal encaminadas a acelerar la igualdad de facto entre el hombre y la mujer no se considerará discriminación en la forma definida en la presente Convención, pero de ningún modo entrañará, como consecuencia, el mantenimiento de normas desiguales o separadas; estas medidas cesarán cuando se hayan alcanzado los objetivos de igualdad de oportunidad y trato”.

Ya no en referencia a las cuotas electorales, sino más en general sobre todo tipo de medidas de acción positiva, se puede también recordar que la Convención Interamericana para la Eliminación de todas las formas de Discriminación contra las Personas con Discapacidad señala que

No constituye discriminación la distinción o preferencia adoptada por un Estado parte a fin de promover la integración social o el desarrollo personal de las personas con discapacidad, siempre que la distinción o preferencia no limite en sí misma el derecho a la igualdad de las personas con discapacidad y que los individuos con discapacidad no se vean obligados a aceptar tal distinción o preferencia. En los casos en que la legislación interna prevea la figura de la declaratoria de interdicción, cuando sea necesaria y apropiada para su bienestar, ésta no constituirá discriminación (artículo 1.2.B).

Al tenor de la normativa que se acaba de mencionar podemos concluir que no hay duda de que el derecho internacional de los derechos humanos acepta perfectamente la existencia de medidas de acción positiva, incluyendo las cuotas electorales; es más, la puesta en práctica de tales medidas es obligatoria para los Estados en orden a proteger a los sujetos más vulnerables de la sociedad (mujeres, minorías etno-culturales y personas con discapacidad, entre otros).

\section{REFERENCIAS}

AGUIAR, Fernando. A favor de las cuotas femeninas. Claves de razón práctica, Madrid, número 116, octubre de 2001.

AÑÓN ROIG, María José. Necesidades y derechos. Un ensayo de fundamentación, Madrid, CEC, 1994.

${ }^{66}$ Consultable en Carbonell, Moguel y Pérez Portilla, Derecho Internacional de los Derechos Humanos. Textos básicos, cit., tomo I, pp. 641-642. 
BELTRÁN, Elena et al.. Feminismos. Debates teóricos contemporáneos, Madrid, Alianza Editorial, 2001.

BERNAL PULIDO, Carlos. El juicio de la igualdad en la jurisprudencia de la Corte Constitucional colombiana. In: VEGA GÓMEZ, Juan y CORZO SOSA, Edgar (coords.), Instrumentos de tutela y justicia constitucional. Memoria del VII Congreso Iberoamericano de Derecho Constitucional, México, IIJ-UNAM, 2002.

El principio de proporcionalidad y los derechos fundamentales, Madrid, CEPC, 2003.

BILBAO UBILLOS, Juan María y REY MARTÍNEZ, Fernando. El principio constitucional de igualdad en la jurisprudencia española. In: CARBONELL, Miguel (compilador), El principio constitucional de igualdad. Lecturas de introducción, México, CNDH, 2003.

BÖCKENFÖRDE, Ernst Wolfgang. La democracia como principio constitucional. In: BÖCKENFÖRDE, Ernst Wolfgang. Estudios sobre el Estado de derecho y la democracia, Madrid, Trotta, 2000.

BOVERO, Michelangelo. Una gramática de la democracia. Contra el gobierno de los peores, traducción de Lorenzo Córdova Vianello, Madrid, Trotta, 2002.

CARBONELL, Miguel y Pérez Portilla, Derecho Internacional de los Derechos Humanos. Textos básicos, México, Porrúa, 2002.

MOGUEL, Sandra y PÉREZ PORTILLA, Karla (compiladores). Derecho Internacional de los Derechos Humanos. Textos Básicos, 2ª edición, México, Porrúa, UNAM, CNDH, 2003.

Una historia de los derechos fundamentales, México, Porrúa, CNDH, 2005.

COMANDUCCI, Paolo. Uguaglianza: una proposta neo-illuminista. In: COMANDUCCI, Paolo y Guastini, Riccardo (orgs.). Analisi e diritto 1992, Turín, Giappichelli, 1992.

DÍEZ PICAZO, Luis María. Sobre la igualdad ante la ley. In: La democracia constitucional. Estudios en homenaje al profesor Francisco Rubio Llorente, Madrid, CEPC, UCM, Tribunal Constitucional, 2002.

DWORKIN, Ronald. Eguaglianza. Enciclopedie delle Scienze Sociali, volumen III, Roma, Istituto della Enciclopedia Italiana, 1993.

. Los derechos en serio, Barcelona, Ariel, 1984.

Sovereing virtue: the theorie and practice of equality, Cambridge, Harvard University Press, 2000.

ELÓSEGUI ITXASO, María, Las acciones positivas para la igualdad de oportunidades laborales entre hombres y mujeres, Madrid, CEPC, 2003.

ELSTER, Jon. La deliberación y los procesos de creación constitucional. In: Elster, Jon (compilador), La democracia deliberativa, Barcelona, Gedisa, 2000.

ELY, John Hart. Democracia y desconfianza. Una teoría del control constitucional, Bogotá, Siglo del Hombre editores, 1997.

ESPING-ANDERSEN, Gosta. Fundamentos sociales de las economías postindustriales, Barcelona, Ariel, 2000.

FERRAJOLI, Luigi. Derecho y razón, 5. edición, Madrid, Trotta, 2000.

Derechos y garantías. La ley del más débil, Madrid, Trotta, 1999.

GIMÉNEZ GLUCK, David, Una manifestación polémica del principio de igualdad: acciones positivas moderadas y medidas de discriminación inversa, Valencia, Tirant Lo Blanch, 1999.

DiReITOS FundaMENTAIS E JUSTIÇA N' 11 - ABR./Jun. 2010 
KEMELMAJER DE CARLUCCI, Aída. Las acciones positivas. In: CARBONELL, Miguel (compilador). El principio constitucional de igualdad. Lecturas de introducción, México, Comisión Nacional de los Derechos Humanos, 2003.

KYMLICKA, Will. Filosofía política contemporánea, traducción de Roberto Gargarella, Barcelona, Ariel, 1995.

LAPORTA, Francisco J. El principio de igualdad: introducción a su análisis, Sistema, número 67, Madrid, 1985

Problemas de la igualdad. In: VALCÁRCEL, Amelia (compiladora), El concepto de

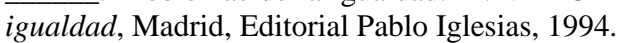

MARTÍN VIDA, María Ángeles. Fundamento y límites constitucionales de las medidas de acción positiva, Madrid, Civitas, 2002.

PAU VALL, Francesc (coord.). Parlamento y sistema electoral. VI Jornadas de la Asociación Española de Letrados de Parlamentos, Madrid, Aranzadi, 2002.

RAWLS, John. Teoría de la justicia. Traducción de María Dolores González, México, FCE, 2002.

RUBIO LLORENTE, Francisco. La forma del poder. Estudios sobre la Constitución, Madrid, CEC, 1993.

RUIZ MIGUEL, Alfonso. La igualdad política. Derechos y libertades, número 11, Madrid, enero-diciembre de 2002.

La representación democrática de las mujeres. In: CARBONELL, Miguel (compilador). El principio de igualdad. Lecturas de introducción, México, Comisión Nacional de los Derechos Humanos, 2003.

Paridad electoral y cuotas femeninas. Claves de razón práctica, número 94, Madrid, julio-agosto de 1999.

VAN PARIJS, Philippe. Libertad real para todos, Barcelona, Paidós, 1996. 